\title{
A contribuição dos Textos de Divulgação Científica para a educação científica
}

\section{The contribution of Scientific Dissemination Texts to science education}

\author{
Kleberson Almeida de Albuquerque ${ }^{1 *}$, Ronilson Freitas de Souza, Danielle Rodrigues Monteiro
} da Costa1, Sinaida Maria Vasconcelos

\begin{abstract}
RESUMO
A divulgação científica proporciona a integração do científico para a sociedade de maneira mais popular e compreensível. Para este fim, são utilizados textos e materiais com linguagem acessível do que a utilizada por aqueles que comumente produzem Ciência, de forma a fomentar investigações e descobertas por parte daqueles que os acessam. Este artigo teve como objetivo central compreender as contribuições dos Textos de Divulgação Científica (TDC) à educação para Ciência. Realizou-se uma pesquisa bibliográfica na plataforma Scientific Electronic Library Online e no Portal de periódicos da Coordenação de Aperfeiçoamento de Pessoal de Nível Superior (CAPES), nos últimos cinco (5) anos, buscando discussões pertinentes a utilização de TDC no ensino de ciências para educação básica. Durante a Análise de Conteúdo (AC) foi possível levantar as seguintes categorias: a) Função social do TDC para a popularização da ciência, b) A utilização de TDC como recurso pedagógico nos Livros Didáticos, e c) $\mathrm{O}$ papel do professor na utilização dos TDC no ensino de ciências. Identificou-se estudos que investigam a utilização destes materiais, no entanto, ainda se faz necessário o aprofundamento em questões sobre a formação de professores para a utilização destes recursos, em vista de se consolidar estas habilidades em todos os níveis formativos, tanto na formação docente inicial quanto na continuada. Foi possível concluir que os TDC possuem uma função social de democratização do conhecimento científico, bem como possibilitam a autonomia e construção coletiva da ciência com seus alunos.
\end{abstract}

Palavras-chave: Textos de Divulgação Científica; Popularização da Ciência; Ensino de Ciências.

\begin{abstract}
Scientific dissemination provides the integration of science into society in a more popular and understandable way. To this end, texts and materials with accessible language are used than those used by those who commonly produce Science, in order to encourage investigations and discoveries by those who access them. This article aimed to understand the contributions of Scientific Dissemination Texts (SDT) to Science education. The bibliographic research was carried out on the Scientific Electronic Library Online platform and on the page of periodicals of the Coordenação de Aperfeiçoamento de Pessoal de Nivel Superior (CAPES), in the last five (5) years, seeking relevant discussions on the use of SDT in science teaching for basic education. During the Content Analysis (CA) it was possible to raise the following categories: a) Social function of SDT for the popularization of science, b) The use of SDT as a pedagogical resource in Textbooks, and c) The teacher's role in the use of SDT in science teaching. Studies were identified that investigate the use of these materials, however, it is still necessary to delve
\end{abstract}

\footnotetext{
${ }^{1}$ Programa de Pós-Graduação em Educação e Ensino de Ciências na Amazônia PPGEECA/UEPA

*E-mail: klebersonalbuquerque@gmail.com
} 
deeper into questions about teacher training for the use of these resources, in order to consolidate these skills at all training levels, both in teacher training initial and ongoing. It was possible to conclude that SDT have a social function of democratizing scientific knowledge, as well as enabling the autonomy and collective construction of science with their students.

Keywords: Scientific Dissemination Texts; Popularization of Science; Science teaching.

\section{INTRODUÇÃO}

Após a Segunda Guerra Mundial, iniciou-se a difusão de uma preocupação com os impactos negativos gerados pelo progresso científico. Diante disto, expandem-se iniciativas que propuseram a popularização da ciência e tecnologia para a sociedade em geral, a fim de que tomassem conhecimento do que estava sendo desenvolvido pela comunidade científica.

Neste sentido, Marandino (2017) aponta que, a partir de 1960, houve inúmeras influências nacionais e internacionais dentro do contexto político e social para o surgimento de uma educação popular, sendo assim, foram criadas políticas públicas de fomento a criação de museus e centros de ciência, além da realização de outros espaços e atividades para a divulgação da ciência. A Divulgação Científica (DC), por sua vez, “compreende a utilização de recursos, técnicas e processos para veiculação de informações científicas e tecnológicas ao público em geral” (BUENO, 1985, p. 1421).

Segundo Demo (2010, p. 17), a "Educação científica se apoia, primordialmente, na expectativa da sociedade intensiva de conhecimento, reconhecendo que a produção de conhecimento inovador se tornou, tanto mais, o divisor de águas em termos de oportunidade de conhecimento". Neste sentido, ela é vista como detentora do potencial para transformação da educação atual, no entanto, para este fim seria necessário cuidar melhor da formação docente, com o intuito de que as aulas não fossem mera reprodução, mas possibilitasse o desenvolvimento da autonomia dos professores e alunos, apontando assim também o seu conceito.

De certo que, a educação científica é altamente difundida em pesquisas científicas. Seja para apontar a pluralidade necessária em sua abordagem diante da complexidade que lhe implica (KRASILCHIK, 1980; LABURÚ; ARRUDA; NARDI, 2003; SANTOS, 2007; BRICCIA; CARVALHO, 2016), ou até mesmo, apresentando a inserção dos indivíduos na cultura científica, a fim de que se possa ter participação nesta, de forma democrática e consciente, oportunizando a melhoria das condições de 
vida da sociedade (GIL-PÉREZ et al., 2001; BIZZO, 2002; KRASILCHIK; MARANDINO, 2004; LEODORO, 2005; SANTOS, 2007; BIZZO; MONTEIRO, 2014). Desta forma, essa aproximação da população com a cultura científica deve estar sendo priorizada em todos os níveis e modalidades de ensino.

Sendo assim, o ensino de ciências possui forte potencial de propiciar esse espaço de inserção dos educandos na cultura científica, bem como pluralidade anteriormente mencionada. No entanto, para tal feito, faz-se necessário levar em consideração a tríade ciência-tecnologia-sociedade dentro da complexidade de seus aspectos sociocientíficos no currículo escolar e até mesmo em espaços não formais de educação, visando o resgate da função social da educação científica (ZANCAN, 2000; KRAPAS; REBELLO, 2001; MARANDINO, 2006; LEAL; GOUVÊA, 2002; SANTOS, 2007). Neste sentido, Santos (2007) apresenta a necessidade de se efetivar uma educação científica crítica dentro da educação básica, questionando os valores e ações do modelo atual de desenvolvimento científico, suas funções sociais e seus impactos na sociedade.

Dando prosseguimento na discussão levantada, a Base Nacional Comum Curricular (BNCC), documento norteador da educação nacional, aponta as competências e habilidades a serem desenvolvidas pelos discentes dentro da disciplina de Ciências, sobretudo direciona que estes aprendam acerca de si mesmos, da diversidade, da evolução e manutenção da vida, do mundo material, do Sistema Solar e Universo, de modo que compreendam, expliquem e intervenham no mundo, aplicando tais conhecimentos científicos nos mais variados contextos.

Dentro do componente curricular de Linguagens, bem como no de ciências naturais, são apresentadas competências e habilidades que se relacionam com a análise e divulgação da ciência, buscando a adesão às práticas de leitura e elaboração de textos de divulgação científica, bem como a problematização dos mesmos, a fim de identificar a veracidade das informações, possibilitando a compreensão de situações-problema, bem como a proposição de soluções com conhecimentos e princípios científicos (BRASIL, 2015).

Neste contexto, foi organizada uma revisão da literatura a partir da questão de pesquisa: Quais as principais contribuições dos textos de divulgação científica para promover a educação científica? Para tanto, partimos da premissa de que as discussões existentes dentro das comunicações científicas atuais sobre a temática podem 
fundamentar o que propomos no presente estudo. Desta forma, objetivamos entender as contribuições dos textos de divulgação científica para a educação científica.

\section{ASPECTOS METODOLÓGICOS}

O presente estudo possui natureza preponderantemente qualitativa, pois atentamos mais aos processos do que somente aos resultados, prevendo a coleta de dados em todo o percurso investigativo (GODOY, 1995; CARDANO, 2017), tendo seu início com dados quantitativos, não levando em consideração a dualidade entre pesquisa quantitativa e qualitativa, como se fossem polos opostos da investigação, mas sim como complementares. A investigação teve seu desenvolvimento inicial durante a disciplina "Análise, adaptação e desenvolvimento de produtos didáticos", ministrada no primeiro período do curso de Mestrado Profissional em Educação e Ensino de Ciências na Amazônia de uma Universidade Pública no primeiro semestre de 2021.

Utilizamos duas bases dados, que continham preferencialmente periódicos brasileiros e de língua portuguesa, primeiramente a Scientific Electronic Library Online (SciELO) e a segunda foi o Portal de periódicos da Coordenação de Aperfeiçoamento de Pessoal de Nível Superior (CAPES). A escolha pelas bases de dados, citadas anteriormente, explica-se pelo fato de possuírem grande repercussão em uma escala internacional, apresentando um elevado número de artigos indexados com significativa relevância para a comunidade científica.

A busca se deu em dois momentos. Inicialmente, para compreensão da dimensão quantitativa de estudos que abordam os textos de divulgação científica, fizemos uma busca sem nenhuma definição de um marcador temporal, como os termos "Textos de divulgação científica" (TDC), em seguida optamos por fazer uma busca avançada restringindo a pesquisa em artigos revisados por pares nos últimos 5 anos (2017-2021), neste momento utilizamos dois campos de busca com os termos "textos" e "divulgação científica". Foi utilizado o operador booleano "AND" com o propósito de restringir a busca para os títulos e demais índices que apresentavam ao mesmo tempo cada um dos termos.

A fim de possibilitar uma melhor compreensão sobre o percurso adotado nas buscas por artigos dentros das bases de dados especificadas anteriormente, estruturamos na Figura 1 uma ilustração sobre o processo de investigação, nela é possível identificar a forma utilizada nas buscas em conjunto com os resultados das mesmas. 
Figura 1 - Percurso de busca

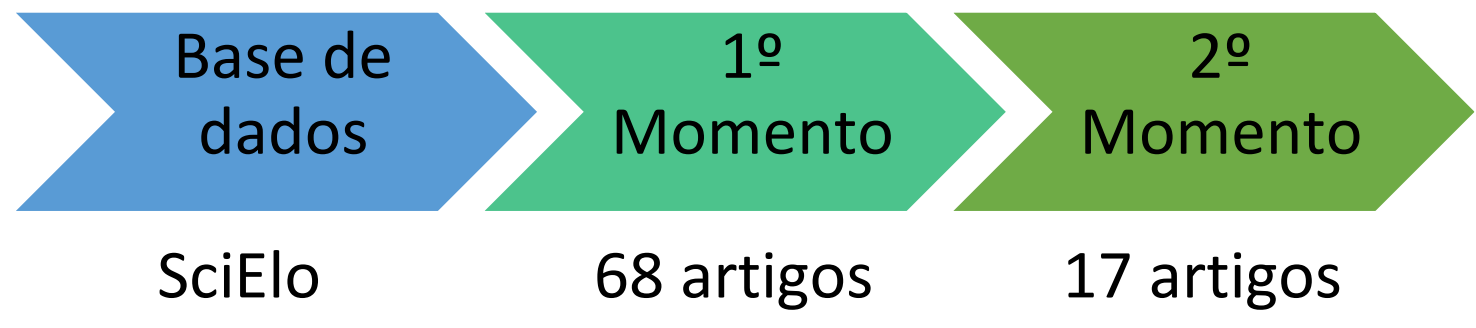

\section{CAPES 295 artigos $\quad 85$ artigos}

Fonte: Os autores (2021)

Foi possível encontrar um total de 363 trabalhos com a realização do primeiro momento de busca (68 na SciElo e 295 na CAPES) e 102 artigos dentro do segundo momento dentro dos parâmetros de busca apresentados (17 na SciElo e 85 na CAPES). Em seguida, os artigos encontrados no segundo momento de busca, foram selecionados em primeiro lugar pela revisão dos títulos e resumos e, por conseguinte, pela revisão do texto completo. Foram incluídos para análise artigos que abordam a temática investigada atrelada ao ensino de ciências na educação básica. Foram excluídos: a) os artigos que não se encontram na faixa temporal de 2017 a 2021, a fim de envolver as discussões mais recentes sobre o assunto; b) Artigos que não possuam seu texto disponível na íntegra; e, c) não discutem a utilização da Divulgação Científica na educação básica.

Tomando por base os parâmetros na busca dos termos especificados anteriormente, podemos observar que há uma expressiva produção de pesquisas que apresentam discussões sobre os textos de divulgação científica. No entanto, somente após a leitura dos trabalhos selecionados no segundo momento, foi possível avaliar o alinhamento entre os artigos encontrados com o objetivo proposto nesta pesquisa.

Após a análise, restaram 12 artigos dentro dos resultados encontrados nas duas plataformas (4 na SciElo e 8 na CAPES), que abordavam de forma mais ampla e clara a relação dos textos de artigos que tratam da Divulgação científica atrelada ao Ensino de Ciências na Educação Básica. 
O procedimento analítico aqui adotado foi a Análise de Conteúdo, preconizada por Bardin (2010). Nos atentamos às três etapas apresentadas na Análise de conteúdo categorial, que consiste inicialmente em uma Pré-análise, onde realizamos uma leitura flutuante dos textos selecionados. Em seguida, partimos para a Exploração do material, codificando os textos, organizando-os em quadros que possibilitem uma fácil compreensão das principais unidades de registro dos resultados apontados. Por fim, partimos para o Tratamento dos resultados e interpretação, que é a etapa final, na qual a análise se debruçou em descrever a relação entre os discursos e as implicações de cada texto, validando as categorias indicadas nas inferências.

No Quadro 1, apresentamos os artigos que compõem o Corpus da revisão bibliográfica, indicando a base de dados onde foram indexados, seu título, autores, ano de publicação, além dos principais achados nestas pesquisas, bem como um código que será utilizado em referências futuras.

QUADRO 1 - Artigos selecionados para análise

\begin{tabular}{|c|c|c|c|c|}
\hline Base & Título & Autor e ano & Principais achados & Código \\
\hline \multirow[t]{3}{*}{ SciElo } & $\begin{array}{ll}\text { Análise } & \text { da } \\
\text { linguagem de } & \text { de } \\
\text { textos } & \text { de } \\
\text { divulgação } & \\
\text { científica em } \\
\text { livros didáticos: } \\
\text { contribuições } \\
\text { para o ensino de } \\
\text { biologia }\end{array}$ & $\begin{array}{l}\text { Pedro } \\
\text { Henrique } \\
\text { Ribeiro de } \\
\text { Souza; } \\
\text { Marcelo } \\
\text { Borges Rocha, } \\
2017 .\end{array}$ & $\begin{array}{l}\text { Os autores constataram que } \\
\text { a articulação entre DC e } \\
\text { Ensino de Biologia, } \\
\text { promovida pelos livros } \\
\text { didáticos, pode contribuir } \\
\text { para a formação de leitores, } \\
\text { no entanto, cabe aos } \\
\text { professores a leitura e } \\
\text { seleção adequada dos textos } \\
\text { para utilizar em suas aulas. }\end{array}$ & $\mathrm{T} 1$ \\
\hline & $\begin{array}{l}\text { Leitura e } \\
\text { argumentação: } \\
\text { potencialidades } \\
\text { do uso de textos } \\
\text { de divulgação } \\
\text { científica em } \\
\text { aulas de Física } \\
\text { do ensino médio }\end{array}$ & $\begin{array}{l}\text { Daniele } \\
\text { Correia; } \\
\text { Emanoela } \\
\text { Decian; Inés } \\
\text { Prieto Schmidt } \\
\text { Sauerwein, } \\
2017 .\end{array}$ & $\begin{array}{l}\text { As autoras verificaram a } \\
\text { importância dos processos } \\
\text { de pré/durante e pós-leitura } \\
\text { dos TDC, para se promover } \\
\text { a articulação entre o texto e } \\
\text { os conhecimentos prévios } \\
\text { dos alunos, bem como a } \\
\text { avaliação de sua } \\
\text { aprendizagem. }\end{array}$ & $\mathrm{T} 2$ \\
\hline & $\begin{array}{lr}\text { O caráter } \\
\text { híbrido } & \text { dos } \\
\text { textos } & \text { de } \\
\text { divulgação } & \\
\text { científica } & \\
\text { inseridos } \quad \text { em } \\
\text { livros didáticos }\end{array}$ & $\begin{array}{l}\text { Pedro } \\
\text { Henrique } \\
\text { Ribeiro de } \\
\text { Souza; } \\
\text { Marcelo } \\
\text { Borges Rocha, } \\
2018 .\end{array}$ & $\begin{array}{l}\text { Defendem que os TDC } \\
\text { apresentam um caráter } \\
\text { híbrido mesmo após a } \\
\text { transposição didática dos } \\
\text { textos científicos, sendo } \\
\text { necessária a leitura prévia } \\
\text { do professor para avaliar o }\end{array}$ & T3 \\
\hline
\end{tabular}




\begin{tabular}{|c|c|c|c|c|}
\hline & & & $\begin{array}{l}\text { comprometimento da } \\
\text { Natureza da Ciência contido } \\
\text { nestes. }\end{array}$ & \\
\hline & $\begin{array}{l}\text { Retextualização } \\
\text { do texto literário } \\
\text { de divulgação } \\
\text { científica A } \\
\text { Tabela Periódica } \\
\text { no ensino de } \\
\text { Química }\end{array}$ & $\begin{array}{l}\text { Arcenira } \\
\text { Resende Lopes } \\
\text { Targino; } \\
\text { Marcelo } \\
\text { Giordan, } 2021 .\end{array}$ & $\begin{array}{l}\text { O estudo constatou que os } \\
\text { TDC devem ser utilizados } \\
\text { para fins pedagógicos, visto } \\
\text { que por meio deles se } \\
\text { podem propor reflexões } \\
\text { referentes aos } \\
\text { conhecimentos científicos } \\
\text { nas aulas de química. }\end{array}$ & $\mathrm{T} 4$ \\
\hline \multirow[t]{4}{*}{$\begin{array}{l}\text { CAPE } \\
\text { S }\end{array}$} & $\begin{array}{l}\text { Discursos sobre } \\
\text { Física } \\
\text { Contemporânea } \\
\text { no Ensino } \\
\text { Médio a partir } \\
\text { da Leitura de } \\
\text { Textos } \\
\text { Divulgação } \\
\text { Científica }\end{array}$ & $\begin{array}{l}\text { Wagner } \\
\text { Moreira Da } \\
\text { Silva; Marcelo } \\
\text { Zanotello, } \\
2017 .\end{array}$ & $\begin{array}{l}\text { Apontam que dentro da } \\
\text { reelaboração discursiva dos } \\
\text { textos científicos para os } \\
\text { Livros didáticos o elemento } \\
\text { mais frequente é de } \\
\text { exclusão, no entanto estes } \\
\text { contribuírem para uma visão } \\
\text { de natureza da ciência, além } \\
\text { de facilitar a compreensão } \\
\text { dos conhecimentos } \\
\text { científicos pelos alunos. }\end{array}$ & T5 \\
\hline & $\begin{array}{l}\text { Análise } \quad \text { de } \\
\text { textos de } \\
\text { divulgação } \\
\text { científica sobre } \\
\text { genética } \\
\text { inseridos em } \\
\text { livros didáticos } \\
\text { de biologia }\end{array}$ & $\begin{array}{l}\text { Bruna Sarpa } \\
\text { Miceli; } \\
\text { Marcelo } \\
\text { Borges Rocha, } \\
2019 .\end{array}$ & $\begin{array}{l}\text { Defendem que os TDC } \\
\text { podem ser utilizados como } \\
\text { recursos didáticos e que há a } \\
\text { necessidade de inserir o } \\
\text { diálogo acerca do uso do } \\
\text { TDC dentro da formação de } \\
\text { professores, a fim de } \\
\text { qualificar o ensino de } \\
\text { Ciências, instrumentalizado } \\
\text { por meio deste recurso. }\end{array}$ & T6 \\
\hline & $\begin{array}{l}\text { Teste genético } \\
\text { preditivo de } \\
\text { câncer de mama: } \\
\text { uma abordagem } \\
\text { discursiva sobre } \\
\text { o uso de texto de } \\
\text { divulgação } \\
\text { científica } \\
\text { histórias e } \\
\text { quadrinhos no } \\
\text { ensino }\end{array}$ & $\begin{array}{l}\text { Flavia Novaes } \\
\text { Moraes; Maria } \\
\text { José Pereira } \\
\text { Monteiro de } \\
\text { Almeida, } \\
2019 .\end{array}$ & $\begin{array}{l}\text { Consideram que é relevante } \\
\text { a utilização de textos de } \\
\text { divulgação científica } \\
\text { atrelados a histórias em } \\
\text { quadrinhos, pois esta } \\
\text { relação constitui um rico } \\
\text { material para ser utilizado } \\
\text { no ensino de ciências, } \\
\text { propiciando a mediação } \\
\text { pedagógica entre o } \\
\text { conhecimento científico e o } \\
\text { conhecimento escolar. }\end{array}$ & T7 \\
\hline & $\begin{array}{l}\text { Textos } \\
\text { divulgação } \\
\text { científica } \\
\text { revista Ciência } \\
\text { Hoje online: } \\
\text { potencial para }\end{array}$ & $\begin{array}{lr}\text { Natália } & \text { de } \\
\text { Paiva } & \text { Diniz; } \\
\text { Mikael } & \text { Frank } \\
\text { Rezende } & \\
\text { Junior, } 2019 .\end{array}$ & $\begin{array}{l}\text { Constatam que há alguns } \\
\text { estereótipos sobre a ciência } \\
\text { na revista "Ciência hoje", } \\
\text { no entanto apontam que os } \\
\text { TDC nelas contidos podem } \\
\text { ser utilizados como recursos }\end{array}$ & T8 \\
\hline
\end{tabular}




\begin{tabular}{|c|c|c|c|}
\hline $\begin{array}{ll}\text { discussão } & \text { de } \\
\text { aspectos } & \text { da } \\
\text { natureza } & \text { da } \\
\text { ciência } & \end{array}$ & & $\begin{array}{l}\text { didáticos por professores na } \\
\text { abordagem de } \\
\text { características da Natureza } \\
\text { da Ciência, sendo necessário } \\
\text { ter conhecimentos prévios } \\
\text { dos temas abordados. }\end{array}$ & \\
\hline $\begin{array}{lr}\text { O Eclipse } & \text { Solar } \\
\text { de } 1919 & \mathrm{em} \\
\text { revistas } & \mathrm{de} \\
\text { divulgação } & \\
\text { científica: } & \\
\text { concepções } \\
\text { sobre natureza } \\
\text { da Ciência e } \\
\text { possíveis } \\
\text { implicações para } \\
\text { o ensino de } \\
\text { Ciências }\end{array}$ & $\begin{array}{l}\text { Lucas } \\
\text { Albuquerque } \\
\text { do } \\
\text { Nascimento, } \\
2019 .\end{array}$ & $\begin{array}{l}\text { O autor defende que é } \\
\text { necessário investir na } \\
\text { formação dos professores de } \\
\text { ciências, para possibilitar } \\
\text { que estes possam } \\
\text { reconhecer as diferentes } \\
\text { concepções da Natureza da } \\
\text { Ciência e História da } \\
\text { Ciência, bem como tenham } \\
\text { aptidão para escolher os } \\
\text { melhores materiais a serem } \\
\text { utilizados em suas aulas, } \\
\text { discutindo com os alunos os } \\
\text { contextos históricos de cada } \\
\text { concepção que for } \\
\text { apresentada nos TDC. }\end{array}$ & T9 \\
\hline $\begin{array}{lr}\text { Análise } & \text { da } \\
\text { natureza } & \text { da } \\
\text { ciência } & \text { em } \\
\text { textos } & \text { de } \\
\text { divulgação } & \\
\text { científica } & \text { sobre } \\
\text { genética } & \\
\text { inseridos } & \text { em } \\
\text { livros didáticos }\end{array}$ & $\begin{array}{l}\text { Bruna Sarpa } \\
\text { Miceli; } \\
\text { Marcelo } \\
\text { Borges Rocha, } \\
2020 .\end{array}$ & $\begin{array}{l}\text { Constataram a predominante } \\
\text { presença de uma visão de } \\
\text { ciência neutra, que não } \\
\text { problematizam } \\
\text { conhecimento científico nos } \\
\text { TDCs que foram } \\
\text { reformulados para LDs. Por } \\
\text { este motivo, recomendam } \\
\text { que os professores utilizem } \\
\text { os TDC em suas duas fontes } \\
\text { para trabalhar em sala de } \\
\text { aula com seus alunos, a fim } \\
\text { maneira a proporcionar uma } \\
\text { reflexão crítica os percursos } \\
\text { históricos da ciência. }\end{array}$ & $\mathrm{T} 10$ \\
\hline $\begin{array}{l}\text { A contribuição } \\
\text { do texto de } \\
\text { divulgação } \\
\text { científica } \\
\text { processo no } \\
\text { ensino de } \\
\text { aprendizagem } \\
\text { dos e } \\
\text { biogeoquímicos }\end{array}$ & $\begin{array}{l}\text { Wagner } \\
\text { Moisés Costa; } \\
\text { Andre } \\
\text { Perticarrari, } \\
2020 .\end{array}$ & $\begin{array}{l}\text { Constataram } \\
\text { articulação dos TDC junto } \\
\text { aos LD, permite aos } \\
\text { professes de ciências a } \\
\text { mediação de um processo de } \\
\text { ensino e aprendizagem mais } \\
\text { eficiente, com r maior } \\
\text { interação dos alunos, } \\
\text { propiciando } \\
\text { aprendizagem significativa. }\end{array}$ & T11 \\
\hline $\begin{array}{lr}\text { Uma } & \text { revisão } \\
\text { acerca do uso de } \\
\text { textos }\end{array}$ & $\begin{array}{l}\text { Camila } \\
\text { Carolina } \\
\text { Colpo; Judite }\end{array}$ & $\begin{array}{l}\text { Em sua análise apontam os } \\
\text { TDC podem ser utilizados } \\
\text { como recursos didáticos em }\end{array}$ & T12 \\
\hline
\end{tabular}




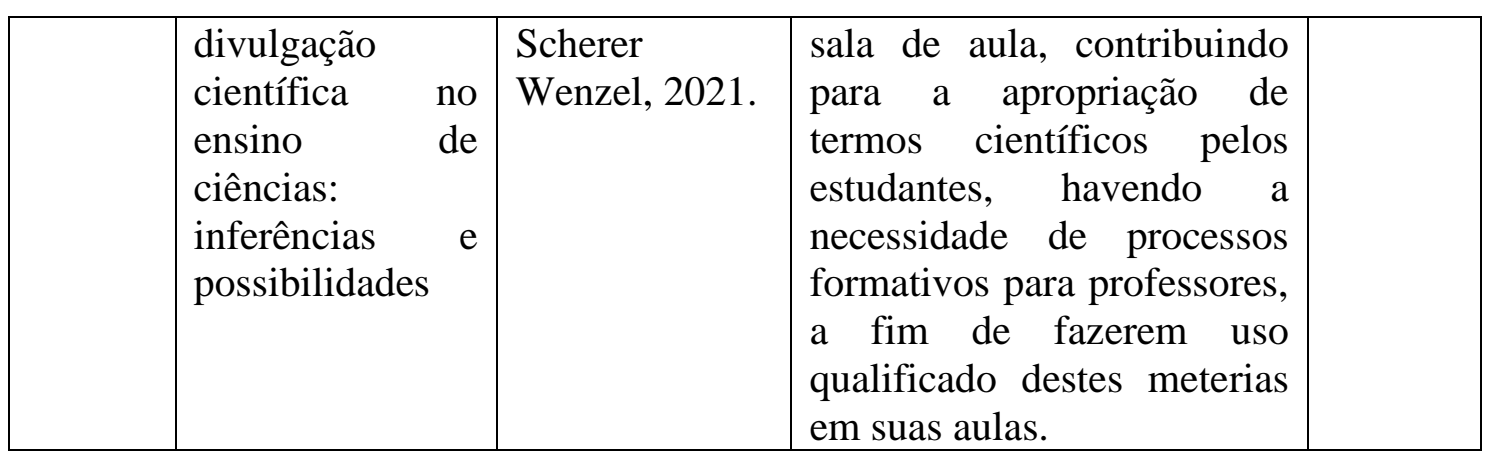

Fonte: Os autores (2021)

Para conseguirmos ter uma visão mais clara sobre os dados apresentados em cada artigo, fizemos uso da plataforma WordClouds.com, a fim de criar uma nuvem de palavras com as principais unidades de registros e sentidos contidas nos textos. Por meio dela, podemos identificar termos que são mencionados com maior frequência, os quais receberam destaque nas discussões levantadas posteriormente.

Figura 2 - Nuvem de palavras com excertos e unidades de registro

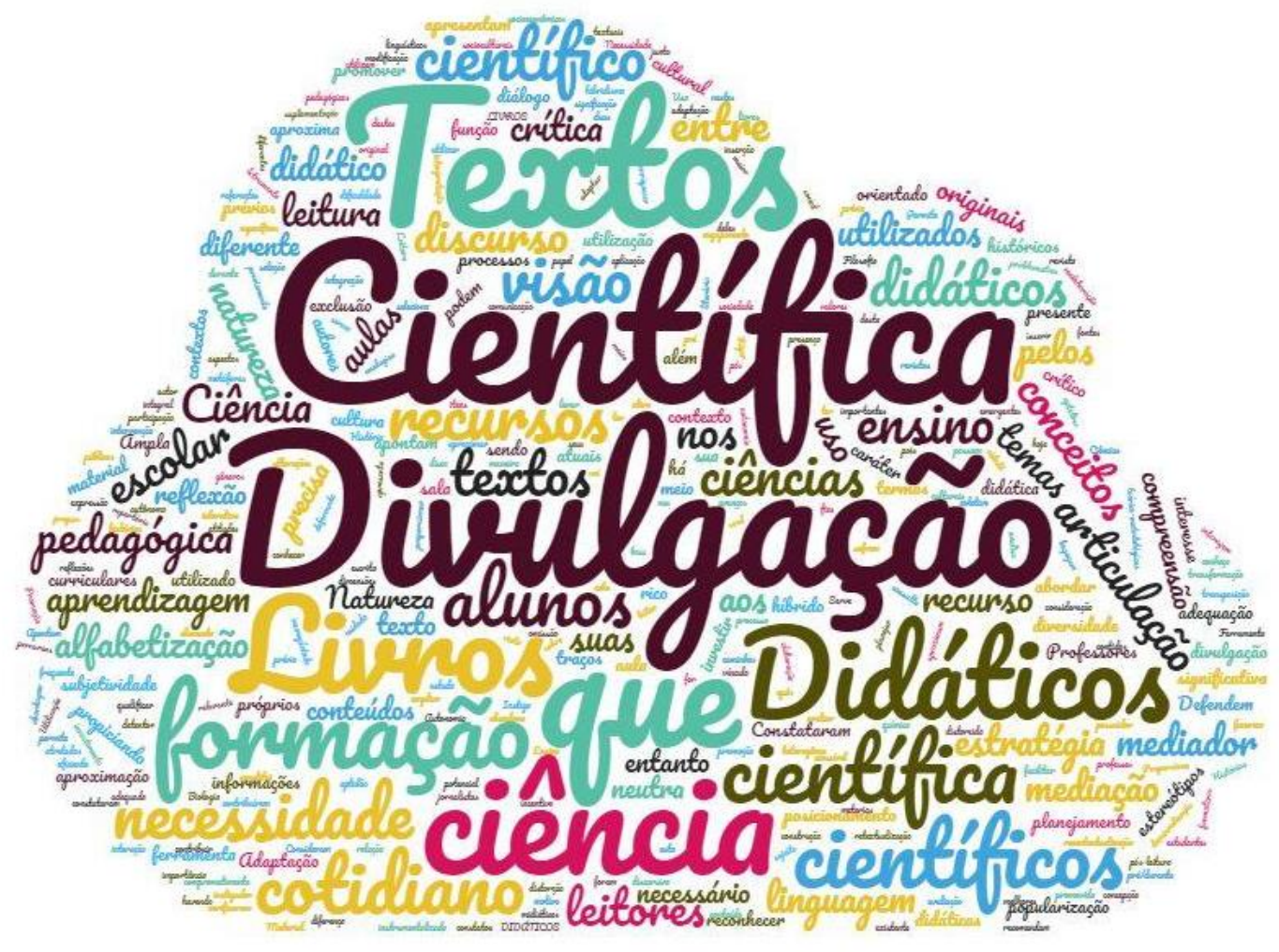

Fonte: Os autores (2021) 
Após a Exploração e codificação dos materiais que compõem o Corpus da pesquisa, podemos inferir algumas categorias que subsidiam a discussão dos resultados apresentados em cada estudo. Para tornar os resultados significativos, alinhamos a análise das 3 categorias levantadas, as quais apresentamos no quadro a seguir.

Quadro 2 - Categorização das unidades de registro

\begin{tabular}{|c|c|c|}
\hline TEXTOS & UNIDADES DE REGISTRO E SENTIDO & CATEGORIAS \\
\hline $\begin{array}{l}\text { T1, T2, T3, } \\
\text { T4, T5, T6, } \\
\text { T7, T8, T9, } \\
\text { T10, T11, } \\
\text { T12. }\end{array}$ & $\begin{array}{l}\text { - } \text { Compreensão de conceitos científicos } \\
\text { - } \text { Ferramenta de contextualização do cotidiano } \\
\text { - Os TDC aproximam da linguagem científica } \\
\text { - Proporciona a alfabetização científica } \\
\text { - Promoção da cultura científica } \\
\text { - Potencial argumentativo participativo }\end{array}$ & $\begin{array}{lrr}\text { Função social do } \\
\text { TDC para } \\
\text { popularização da } \\
\text { ciência }\end{array}$ \\
\hline $\begin{array}{l}\text { T1, T2, T3, } \\
\text { T7, T8, } \\
\text { T10, T11, } \\
\text { T12 }\end{array}$ & $\begin{array}{l}\text { - Material de mediação pedagógica } \\
\text { - TDC como recurso didático } \\
\text { - Utilização do TDC como estratégia } \\
\text { pedagógica } \\
\text { - TDC como detentor de potencialidades } \\
\text { didáticas }\end{array}$ & \multirow[t]{2}{*}{$\begin{array}{l}\text { A utilização de } \\
\text { TDC como } \\
\text { recurso } \\
\text { pedagógico nos } \\
\text { Livros Didáticos }\end{array}$} \\
\hline $\begin{array}{l}\text { T1, T3, T4, } \\
\text { T5, T6, } \\
\text { T10, T12. }\end{array}$ & $\begin{array}{l}\text { - Adaptação dos TDC em Livros Didáticos } \\
\text { - TDC como possuidor de traços próprios } \\
\text { - A diferença existente entre o texto científico } \\
\text { original e o presente nos Livros Didáticos }\end{array}$ & \\
\hline $\begin{array}{l}\text { T2, T5, T6, } \\
\text { T8, T9, } \\
\text { T10, T11, } \\
\text { T12. }\end{array}$ & $\begin{array}{l}\text { - Professor como mediador } \\
\text { - Professor autônomo } \\
\text { - A necessidade de investimento na formação de } \\
\text { professores } \\
\text { - A necessidade de planejamento prévio } \\
\text { - Uso dos TDC orientado pelo professor } \\
\text { - Professor como instigador de interesse dos } \\
\text { alunos } \\
\text { - A necessidade de que o professor conheça os } \\
\text { textos originais } \\
\text { - Adaptação e adequação do discurso presente } \\
\text { nos TDC pelo professor }\end{array}$ & $\begin{array}{l}\text { O papel do } \\
\text { professor na } \\
\text { utilização dos } \\
\text { TDC no ensino de } \\
\text { ciências }\end{array}$ \\
\hline
\end{tabular}

Fonte: Os autores (2021)

A seguir analisamos as categorias levantadas. Neste momento, faremos uso de alguns excertos que referenciam as unidades de registro e sentido supracitadas, alinhadas as seguintes categorias: a) Função social do TDC para a popularização da ciência, b) A utilização de TDC como recurso pedagógico nos Livros Didáticos, e c) $O$ papel do professor na utilização dos TDC no ensino de ciências. 


\section{ANÁLISE E DISCUSSÃO DE RESULTADOS}

\section{Função social do TDC para a popularização da ciência}

É unânime, entre os trabalhos presentes no corpus da pesquisa, a defesa de que os TDC contribuem diretamente para a consolidação da cidadania. A tomada de consciência sobre Ciência e Tecnologia (C\&T), possibilita a inserção de forma ativa e crítica na sociedade, entendendo os problemas e benefícios causados pelo avanço da Ciência. Nesta perspectiva, os TDC se apresentam como recursos didáticos a fim de que os alunos tenham conhecimento de termos científicos, levando-os a significação dos mesmos. Estes textos possuem uma linguagem específica que estabelece os conceitos cotidianos e a relação com os conceitos científicos.

A aproximação do conhecimento científico do escolar é abordada de diversas formas. A exemplo do T7, que busca abordar a utilização de texto de DC em Histórias em Quadrinhos (HQ). As autoras discorrem sobre sua bem-sucedida experiência na utilização de HQs atreladas a TDC em aulas de ensino de biologia na educação básica. Neste texto é apontada a potencialidade de levar a complexidade de temáticas do ensino de ciências para as aulas por meio de imagens e textos que os HQs possuem, ampliando assim a percepção dos alunos sobre as temáticas abordadas.

Para as autoras do T7, os conhecimentos presentes no ensino de ciências possibilitam uma educação para saúde, sendo esta uma função social do conhecimento científico, justificando a importância de se trabalhar conhecimentos relevantes ao autocuidado e à disseminação de informações sobre o cuidado com a saúde para os alunos e a sociedade em geral. Neste sentido, as autoras apontam que educação científica é propulsora da formação humana dos sujeitos, possibilitando por meio dela a democratização dos conhecimentos historicamente construídos pela ciência despertando os alunos para o posicionamento crítico e reflexivo diante da sociedade tendo participação ativa nela.

Outra forma de abordagem é apresentada no T4, no qual os autores apresentam a DC presentes nos textos literários analisando a aplicação de uma sequência didática no ensino de química no primeiro ano do ensino médio em escola pública de São Paulo. Foi destacada a diversidade de discursos presentes na sala de aula, favorecendo a formação integral dos estudantes no ensino de ciências, tal qual para o letramento 
científico, habilitando os indivíduos para decodificar informações científicas refletindo sobre elas, a fim de tomar decisões responsáveis na sociedade onde se insere.

A possibilidade da aproximação dos conhecimentos científicos do cotidiano dos alunos é algo amplamente abordado nos textos analisados. Os conhecimentos presentes no TDC podem ser apropriados pelos educandos por possuírem uma linguagem mais acessível, utilizando diversos recursos, como linguagem coloquial, metáforas, figuras e outras representações vistas como favoráveis para o processo de ressignificação no ensino de ciências, democratizando tais conhecimentos (T1, T5, T6, T8, T10, T11).

O processo de apropriação e significação de termos científicos acontece em sala de aula durante a utilização dos TDC, mediante a aproximação do contexto em que está inserida a realidade da escola, bem como a relação com o cotidiano dos alunos. No entanto, mesmo que esses textos não tragam tal proximidade com o cotidiano, também podem ser contextualizados pelos professores e alunos, visto que a simplificação de conceitos científicos nos TDC podem trazer falhas no sentido do discurso da ciência, com simplificações que tornaram conhecimento raso, que caso estejam incorretos, podem contribuir assim para uma falta de aprendizagem adequada dos estudantes, estando aí umas das principais participações dos professores neste contexto, que discutiremos mais adiante.

Com a apropriação dos significados científicos pelos estudantes, eles podem não somente ressignificar a ciência em uma linguagem cotidiana, mas inserir esses conhecimentos em seu cotidiano, a fim de propor transformações significativas. O T12 defende a importância de considerar o uso adequado dos termos científicos e também de propor espaços de ensino que promovam a sua significação, sendo assim, a utilização do TDC “contribui para o processo de significação dos conceitos em sala de aula, pois impõe ao estudante se posicionar frente ao texto, e que tal posicionamento só se torna possível mediante atribuição de significado a ele" (COLPO; WENZEL, 2021, p.17). Nas aulas de ciências naturais, o TDC pode contribuir nessa significação conceitual do conhecimento científico aos alunos, visto que eles chamam a atenção dos alunos, e os aproximam do fazer científico, contribuindo para a argumentação em sala de aula, apresentando seus posicionamentos frente às temáticas discutidas.

Neste seguimento, os TDC quando utilizados em sala de aula, podem contribuir para abranger a complexidade das discussões presentes no ensino de ciências, "mas também promover o desenvolvimento de habilidades relacionadas a expressões oral e 
escrita necessárias a formação do cidadão crítico capaz de se posicionar e argumentar sobre o que lê" (DECIAN; SAUERWEIN, 2017, p. 1018). Estes recursos oferecem diversidade de informações e apropriação de conceitos, bem como a formulação de argumentação, suscitando assim "as habilidades relacionadas às expressões oral e escrita só serão desenvolvidas com a intenção de práticas frequentes e periódicas de leitura” (DECIAN; SAUERWEIN, 2017, p. 1020).

Destarte, os TDC apresentam um potencial argumentativo e participativo na sala de aula, possibilitando a aproximação do conhecimento científico do cotidiano dos alunos, desenvolvendo também habilidades de leitura e escrita, tal como a capacidade de argumentação. Nesta mesma perspectiva, os autores do T1 ressaltam que é importante também a utilização de textos com a linguagem mais científica nas aulas de ciências, pois possibilita que os alunos se apropriem do discurso científico mesmo que aos poucos, tendo domínio da argumentação científica.

Neste sentido, os autores apontam também a importância da disposição dos alunos para a efetivação do processo de ensino-aprendizagem, sendo isto, possibilitado na utilização dos TDC no ensino de ciências, acrescido da mobilização e interação na leitura, bem como a discussão das temáticas apresentadas por estes, despertando o interesse dos alunos, junto a uma aula mais aberta ao diálogo.

Os TDC enriquecem as aulas e motivam os alunos, tendo sua utilização mais eficiente atrelada aos Livros Didáticos (LD), pois um complementa o outro, integrando conhecimentos tendo a mediação do professor para contextualizar os conhecimentos científicos ao cotidiano dos alunos para uma aprendizagem significativa (T11). Corroborando com esta ideia, os autores do T5 apontam que a utilização de TDC no ambiente escolar pode possibilitar a compreensão de conhecimentos que muitas vezes não estão atrelados de forma explícita dentro da grade curricular, possibilitando uma formação humana e cidadã aos alunos, por meio de discussões sobre conhecimentos científicos em uma linguagem mais acessível.

A utilização dos TDC nas aulas de ciências apresenta uma possibilidade para o diálogo e abertura de discussões de temas emergentes contextualizados por estes recursos, viabilizando assim o exercício da reflexão crítica sobre conhecimento científico atrelada ao cotidiano. Esta criticidade, por sua vez, se torna propulsora da compreensão da Natureza da Ciência (NdC) dentro do ambiente escolar, auxiliando no 
entendimento do caráter inacabado da ciência, suscitando a relação desta com a sociedade, por meio de questões socioambientais e éticas.

Os autores do T8 defendem que o TDC possui potencial de levar para as aulas de ciências informações sobre a dimensão teórico-metodológica do fazer científico, possibilitando que os alunos tenham a compreensão sobre a construção dos conhecimentos científicos em diferentes tipos de pesquisa, sobre a formulação de hipóteses e as limitações da ciência, além da possibilidade de desmistificar a existência de um único método científico. Para isto, o autor do T5 também apresenta a importância de oferecer escolhas sobre as leituras aos alunos, suscitando assim um envolvimento e participação ativa na organização das atividades, propiciando o desenvolvimento de funcionamento crítico e autônomo dos mesmos, a fim de que se tornem protagonistas no processo de ensino e aprendizagem, além de sujeitos socialmente participativos, inseridos em seu tempo e sua sociedade.

Para a efetivação desta formação cidadã é necessário o estabelecimento de uma perspectiva crítica sobre os conhecimentos científicos existentes, aproximando os alunos de discussões sobre a História e Filosofia da Ciência, bem como da NdC. Tornase imprescindível assim, a discussão dos objetivos e influências sofridas ou causadas sobre a sociedade e época em que eles surgem, não limitando o pluralismo metodológico e aceitação ou rejeição de ideias científicas, bem como os equívocos cometidos pelos cientistas e o caráter provisório dos conhecimentos científicos vigentes (T3, T5, T8, T9, T10).

Neste sentido, para além das escolas, os TDC possuem um alcance maior na disseminação desses conhecimentos científicos para a população em geral por meio de revistas, jornais e outros meios. Sendo assim, para possibilitar uma postura crítica frente ao progresso científico e aos impactos positivos e negativos em decorrência destes se faz necessário que os TDC possuam uma linguagem acessível e que sejam de fácil adaptação, para que caso seja necessário sofrer modificações na linguagem, alcancem públicos de diferentes condições sociais, culturais e econômicas.

Alguns autores apresentam inconsistências na $\mathrm{NdC}$ existente nos TDC, no entanto, estes não precisam ser descartados e inutilizados, pois eles podem auxiliar na discussão que a $\mathrm{NdC}$ possui com as transições de paradigmas científicos. Tais inconsistências, podem subsidiar discussões sobre a dimensão histórico-temporal da construção do conhecimento científico, abordando controvérsias da ciência, bem como a 
transitoriedade do conhecimento, oferecendo assim uma visão ampla da NdC. Neste sentido, tal abordagem pode propiciar a compreensão dos métodos que eram utilizados no tempo passado e métodos atuais, bem como a forma com que essa produção influencia na sociedade atual, sendo essencial mencionar a construção coletiva da ciência.

Diante da importância dada pelos textos encontrados sobre a utilização dos TDC, os mesmos defendem a necessidade da proposição de mais pesquisas que visem analisar a utilização dos TDC em diversos contextos educativos. Além disso, apontamos como significativa a presença de relatos de experiências do emprego dos TDC no ensino de ciências, como apresentado nos textos T2 e T7, que trouxeram consideráveis contribuições para o presente escrito, estabelecendo a função social da educação para saúde, bem como a atenção momentos de pré, durante e pós leitura dos TDC, levando em consideração o processo de utilização destes materiais, de forma mais complexa.

\section{A utilização de TDC como recurso pedagógico nos Livros Didáticos}

Em quase todos os artigos encontrados, o TDC foi apresentado como material de mediação pedagógica ou como recurso didático, seja dentro de revistas especializadas que fornecem estes materiais ou os que estão presentes nos Livros Didáticos (LD) (T1, T2, T3, T7, T8, T10, T11, T12). Os TDC contidos nos LD sofrem adaptações, que por sua vez adquirem traços próprios que não somente os pertencentes a $\mathrm{DC}$, possuindo significações dos conhecimentos científicos e escolares, assumindo um caráter híbrido para a aproximação do cotidiano dos estudantes (T1, T3, T4, T5, T6, T10, T12).

Os autores do T1 defendem que há limitações na utilização dos TDC presentes nos LD. Afirmam que os mesmos apresentam barreiras de natureza epistemológica, não abordando a complexidade dos fenômenos científicos de forma acessível aos alunos. Sendo assim, a diferença existente entre o texto científico original e o presente nos LD se torna um fator a ser observado também por outros autores, que assim como o T10, aponta que a maioria dos textos apresenta uma visão de ciência neutra, deixando assim de problematizar o conhecimento científico.

Neste sentido, existe a importância de se utilizar o LD atrelado aos TDC originais em sala de aula, a fim de mitigar os problemas causados por uma perspectiva deformada da ciência, visando à abertura de discussões de forma mais crítica sobre os avanços e caminhos da ciência presentes nestes textos. Corroborando com esta ideia, os 
autores do T11 apontam que o uso dos TDC pode complementar a discussão sobre ciências no LD, a fim de aproximar o conhecimento científico do cotidiano dos alunos, por meio da contextualização do conhecimento científico no conhecimento escolar.

A utilização dos LD e dos TDC pelo professor no ensino de ciências contribui com o diálogo dos sujeitos, possibilitando a formação de novos conceitos com base em suas estruturas mentais pré-estabelecidas. Desta forma os autores defendem a importância de se utilizar o LD e também os TDC em sala de aula a fim de relacionar e discutir de forma mais crítica os avanços e caminhos da ciência presentes nestes textos.

Sobre o processo de reescrita dos TDC para os LD, o texto T5 aponta que, ao reescreverem não fazem apenas uma mera tradução do conhecimento científico, mas a construção de um novo tipo de texto com uma formação discursiva direcionada a um público amplo fora da comunidade científica. Nestes, são constatadas também as representações subjetivas dos autores com sua relação às imagens e conceitos apresentados dentro dos TDC. Desta forma, os alunos acabam construindo relações simbólicas com as discussões presentes dentro dos TDC, interagindo de forma crítica e reflexiva sobre os temas contemporâneos apresentados neles.

Ademais, o T5 apresenta a existência da singularidade dos TDC, visto que não devem ser abordados da mesma forma que textos de outros gêneros, presentes dentro do LD. Os TDC precisam ser abordados tendo o reconhecimento que as situações de aprendizagem não se limitam a conceitos e ao fornecimento de respostas prontas. Podem proporcionar, assim como defendido no T6, o desenvolvimento de aptidões leitoras, com uma leitura e interpretação de textos de forma dialógica e crítica. Estando de acordo com o T1, ao apontar o reconhecimento de figuras de linguagens, como, metáforas, analogias e outros termos explicativos, dentro dos TDC, a fim de aproximar os leitores de uma forma mais compreensiva do conhecimento científico.

Os TDC, dentro do LD, torna-os mais atrativos e contextualizados aos conteúdos curriculares, atuando assim como motivadores para os alunos. No entanto, sofrem alterações ao serem transpostos para os livros didáticos, passam por adaptações que consistem na "reelaboração discursiva, que promovem alterações no texto original" (MICELI; ROCHA, 2019, p. 1046). Desta maneira, torna-se importante a interação dos TDC no LD, pois os mesmos devem apresentar a ciência como dinâmica e não estática, propondo um discurso que aproxima os conhecimentos do cotidiano. 
Diante das diversas formas de apresentar a NdC nos TDC, quando estes são modificados e inseridos dentro dos LD, se torna ainda mais importante a atuação do professor ao utilizar os TDC originais juntamente com os LD. Essa associação e a utilização de textos com a natureza deformada da ciência podem servir para um direcionamento crítico do professor, a fim de que seja proposto em aula, o que também é apresentado no T6, a problematização de que a ciência ainda precisa de pesquisas, que a mesma é inacabada e não é realizada de forma instantânea, além de ser passível de falhas.

\section{O papel do professor na utilização dos TDC no ensino de ciências}

Há diferentes abordagens quanto ao papel do professor na utilização de TDC em suas aulas. Em grande parte dos artigos analisados, o professor é apresentado como o mediador do processo de aprendizagem com a utilização destes textos, tendo ele a autonomia para planejar de forma adequada esta aplicação, bem como a seleção dos textos e incentivo aos alunos. Além disso, diante de erros conceituais presentes nestes materiais, estes devem ser utilizados pelos professores para discutir de forma crítica com os alunos, utilizando isso como uma estratégia para promover o entendimento e respeito às condições das produções de materiais de divulgação Científica.

Os autores do T2 defendem que a utilização das três etapas pré, durante e pós leitura possibilita aos professores avaliar os resultados de aprendizagem dos alunos durante todo o processo. Neste sentido, o professor se incumbe do planejamento adequado para a utilização do TDC, estando em consonância com T4, ao afirmar que "cabe ao professor realizar movimentos discursivos de adequação do discurso apresentado no material a nova esfera de circulação" (TARGINO; GIORDAN, 2021, p. 3), visto que mesmo diante da linguagem mais acessível, ainda existem dificuldades para que os estudantes, interpretem TDC, destarte, este planejamento onde os estudantes podem participar de forma ativa, possibilita a interação entre aluno e professor, aluno e aluno, assim como de professor e alunos no processo discursivo argumentativo em sala de aula.

Os autores do texto T11 apontam a necessidade de que o professor conheça os textos originais, a fim de que possa mediar o processo de ensino e aprendizagem de forma mais rica, onde os alunos possam ter participação ativa e dialógica contribuindo para a aprendizagem significativa dos mesmos. Neste ínterim, se fazem necessárias 
também a adaptação e adequação do discurso presente nos TDC pelo professor, visto que, assim como apresentado pelo T3, estes textos apresentam concepções atuais ou não sobre a NdC. Estes materiais são potencializados pelo uso da História e Filosofia da Ciência (HFC), precisando da mediação do professor, relacionando as concepções menos atuais da $\mathrm{NdC}$, identificando que todas as concepções e paradigmas estão relacionados a determinados períodos históricos.

Neste mesmo sentido, os autores do T12 também apontam que a utilização de TDC se constitui em um caminho de potencialidade para a aproximação dos estudantes de temáticas científicas. Estes textos apresentam os conhecimentos científicos de forma contextualizada e dinâmica, a fim de que os alunos se apropriem desses conhecimentos dando significado a eles, sendo necessária a mediação do professor por meio de estratégias de compreensão e significação de temáticas científicas. Sendo assim, os professores atuam como interventores, exercendo autonomia, recomendando uma leitura crítica e desenvolvendo outras metodologias de ensino com seus alunos.

Tendo isto em vista, "recomenda-se que os professores consultem os textos originais, pois assim podem evitar quaisquer informações errôneas e identificar concepções distorcidas a respeito da natureza da ciência nos textos inseridos" (SOUZA; ROCHA, 2018, p. 1058). Em acordo com o T10, defende que esta relação pode aproximar da compreensão da natureza da ciência quando não são retratados no livro didático, aprofundando assim o entendimento dos alunos dentro dos conhecimentos discutidos.

O T8 defende que há diversos tipos de TDC que apresentam a NdC de maneira igualmente diversa. Alguns destes textos apresentam visões distorcidas sobre a ciência, apresentando essa como método imutável e irrefutável. Assim, são necessárias a argumentação e a discussão de alunos e professores sobre diferentes pontos de vista, a fim da superação de uma visão única da ciência, para que os alunos possam compreender as diferentes formas através das quais a ciência é construída.

Corroborando com a ideia anterior, o T8 defende que o professor assume o papel de mediador, intervindo nos momentos nos quais sejam apresentadas imagens deformadas da ciência. Logo, o professor precisa ter uma atenção especial em sua leitura e seleção dos textos que utilizará em aula. De tal modo, conforme apresentado no T12, o professor deve tomar muito cuidado ao escolher os TDC que irá utilizar em suas aulas. É necessário ver o que melhor se adequa a realidade em que está inserido e como 
os conceitos que estão presentes nesses textos chegarão aos seus estudantes. Ademais, é preciso também propiciar espaços para o diálogo com os estudantes, partindo de uma leitura interativa dos TDC mediada pelo professor, potencializando o posicionamento do estudante frente ao que está lendo.

Os autores do T12 apontam que a utilização de TDC nas aulas de ciências se constitui de um potencial caminho para a aproximação dos estudantes de temáticas científicas, estes textos apresentam os conhecimentos científicos de forma contextualizada e dinâmica, a fim de que os estudantes se apropriem desses conhecimentos dando significado a eles, sendo necessária a mediação do professor por meio de estratégias de compreensão e significação de temáticas científicas.

Tendo continuidade, o TDC por si só não se constitui em uma aprendizagem ideal, pois ainda apresenta conceitos de difícil compreensão pelos alunos. Neste sentido, se faz necessária a intervenção e mediação do professor de forma planejada. Então, primeiramente, estes materiais devem ser apresentados aos professores tanto na sua formação Inicial, como na continuada, para que posteriormente ele possa fazer o uso de forma eficaz desses recursos em suas aulas. Tal concepção está em conformidade com o T11, visto que ele constata a necessidade que o professor possui de se apropriar dos conhecimentos presentes no TDC, a fim de poder comentar situações que possibilitam ao aluno integrar conhecimentos científicos ao que tem sido discutido atualmente na sociedade.

Os autores do T11 defendem que a ação do professor é essencial na mediação e aproximação dos conhecimentos científicos presentes no LD. Mesmo que a construção destes conhecimentos tenha se dado de forma histórica e social, cabe ao professor relacionar tais conhecimentos aos precursores dos alunos, possibilitando aprendizagem significativa dos mesmos, atrelando assim os conhecimentos originários dos indivíduos aqueles de caráter científico, historicamente construído.

Diante do papel do professor na mediação desse conhecimento, o autor do T3 aponta a importância de se investir na formação inicial e continuada dos professores de ciências, a fim de que eles possam reconhecer essas concepções de natureza da ciência e do trabalho científico utilizando de forma adequada os TDC e LD por eles utilizados no ensino de ciências. Neste mesmo ínterim, o autor do T9 defende a necessidade de se investir na formação de professores para possibilitar que os mesmos consigam reconhecer concepções acerca da natureza do conhecimento científico presentes nos 
textos de divulgação Científica, a fim de que possam desenvolver de forma adequada no ensino de ciências.

\section{CONSIDERAÇÕES FINAIS}

Diante das discussões apresentadas, compreende-se a importância dos Textos de Divulgação Científica para o ensino de ciências. Este recurso contribui para o desenvolvimento da cidadania, com a participação de um número maior de pessoas que compreende a contribuição dos conhecimentos científicos, introduzindo-os de forma simplificada à população, podendo ser acessado por pessoas de formações variadas.

Mesmo diante dos estudos existentes sobre a temática, ainda se faz necessário o aprofundamento de pesquisas que proponham compreender tanto a aplicação do TDC no ensino de ciências, quanto o papel do professor neste contexto. No entanto, é unânime na literatura investigada, a defesa de que estes materiais possibilitam a ampla difusão dos conhecimentos científicos, tendo assim um comprometimento com a cidadania dos educandos, além de possibilitar a contextualização com a realidade onde estão inseridos, indagando problemas relevantes para eles, dando suporte aos livros didáticos e não os excluindo, mas fazendo uso de ambos para propor soluções que proporcionem qualidade vida à população.

Outro apontamento importante é que a formação de professores precisa contemplar os conhecimentos sobre a utilização dos TDC no contexto escolar, pelo fato de possibilitar a autonomia docente na escolha adequada dos textos e métodos de utilização destes. Neste sentido, os professores devem possuir o domínio argumentativo para discutir de forma coletiva com seus alunos, textos que apresentam uma visão de ciência deformada, levando em consideração que os TDC não devem ser vistos como instrumentos isolados e estáticos, pelo contrário, é necessário que os professores sejam dotados de conhecimentos para avaliar estes materiais, de forma que possam adaptá-los e criar novos que supram as necessidades de onde se insere.

Por fim, dentro da análise identificamos como função social do TDC a contextualização do conhecimento científico, como propulsores de democratização para a participação crítica e ativa na sociedade. Compreendemos que os TDC são importantes recursos pedagógicos dentro dos $\mathrm{LD}$, onde recebem um novo caráter discursivo com características próprias de conhecimento científico e escolar, aproximando-se mais do cotidiano dos alunos. Além disso, percebemos que a principal 
abordagem sobre o papel do professor na utilização dos TDC consiste na visão de um professor mediador, que possui autonomia e responsabilidade sobre a escolha e condução metodológica de aplicação destes textos em suas aulas, bem como identificamos a necessidade de formação inicial e continuada de professores para que os professores conheçam estes recursos e desenvolvam habilidades de como usá-los.

\section{REFERÊNCIAS}

BARDIN, L. Análise de conteúdo. 4. ed. Lisboa: Edições70, 2010.

BIZZO, N. Reflections upon a national program assessing Science textbooks: what is the importance of content in Science education? In: Anais do Proceedings of the 10th IOSTE Symposium, Foz do Iguaçu, p. 710-720, 2002.

BIZZO, N.; MONTEIRO, P. H. N. Possíveis relações entre livros didáticos e mortalidade causada por acidentes ofídicos no Brasil no período 1993-2007: o papel da educação científica na sociedade. Cadernos de História da Ciência, v. 10, n. 2, 2014.

BRASIL. Ministério da Educação. Base Nacional Comum Curricular - $1^{\text {a }}$ versão. Brasília: MEC, 2015.

BRICCIA, V.; CARVALHO, A. M. P. Competências e formação de docentes dos anos iniciais para a educação científica. Ensaio Pesquisa em Educação em Ciências (Belo Horizonte), v. 18, p. 01-22, 2016.

BUENO, W. C. Jornalismo científico: conceitos e funções. Ciência e Cultura, n. 37, v. 9, p. 1420-1428, set. 1985 .

CARDANO, M. Manual de pesquisa qualitativa. A contribuição da teoria da argumentação. Tradução: Elisabeth da Rosa Conill. Petrópolis, Rio de Janeiro: Vozes, 2017.

COLPO, C. C.; WENZEL, J. S. Uma revisão acerca do uso de textos de divulgação científica no ensino de ciências: inferências e possibilidades. Alexandria: Revista de Educação em Ciência e Tecnologia, v. 14, n. 1, p. 3-23, 2021.

CORREIA, D.; DECIAN, E.; SAUERWEIN, I. P. S. Leitura e argumentação: potencialidades do uso de textos de divulgação científica em aulas de Física do ensino médio. Ciência \& Educação (Bauru), v. 23, p. 1017-1034, 2017.

COSTA, W. M.; PERTICARRARI, A. A contribuição do texto de divulgação científica no processo de ensino e aprendizagem dos ciclos biogeoquímicos. Revista Prática

Docente, v. 5, n. 2, p. 922-943, 2020.

DEMO, P. Educação científica. Boletim Técnico do Senac, v. 36, n. 1, p. 15-25, 2010. 
DINIZ, N. P.; REZENDE JUNIOR, M. F. Textos de divulgação científica da revista Ciência Hoje online: potencial para discussão de aspectos da natureza da ciência. Alexandria: Revista de Educação em Ciência e Tecnologia, v. 12, n. 2, p. 165194, 2019.

GIL-PÉREZ, D.; MONTORO, I. F.; ALÍS, J. C.; CACHAPUZ, A.; PRAIA, J. Para uma imagem não deformada do trabalho científico. Ciência \& Educação, v.7, n.2, p.125$153,2001$.

GODOY, A. S. Introdução à pesquisa qualitativa e suas possibilidades. Revista de administração de empresas, v. 35, n. 2, p. 57-63, 1995.

KRAPAS, S.; REBELLO, L.. O perfil dos museus de ciência da cidade do Rio de Janeiro: a perspectiva dos profissionais. Revista Brasileira de Pesquisa em Educação em Ciências, v. 1, n. 1, 2001.

KRASILCHIK, M. Inovação no ensino das ciências. In: GARCIA, W. E. (Org.). Inovação educacional no Brasil: problemas e perspectivas. São Paulo: Cortez; Campinas: Autores Associados, p.164-180, 1980.

KRASILCHIK, M.; MARANDINO, M. Ensino de ciências e cidadania. São Paulo: Moderna, 2004.

LABURÚ, C. E.; ARRUDA, S. M.; NARDI, R. Pluralismo metodológico no ensino de ciências. Ciência \& Educação (Bauru), v. 9, n. 2, p. 247-260, 2003.

LEAL, M. C.; GOUVÊA, G. Narrativa, mito, ciência e tecnologia: o ensino de ciências na escola e no museu. Ensaio: pesquisa em educação em ciências, v. 2, n. 1, p. 5-36, 2002.

LEODORO, M. P. Pensamento, cultura científica e educação. (Tese de Doutorado). Universidade de São Paulo, 2005.

MARANDINO, M. Faz sentido ainda propor a separação entre os termos educação formal, não formal e informal?. Ciência \& Educação (Bauru), v. 23, n. 4, p. 811-816, 2017.

MARANDINO, M.. Perspectivas da pesquisa educacional em museus de ciências. In: SANTOS, Flávia Maria Teixeira dos; GRECA, Ileana Maria (Orgs.). A pesquisa em ensino de ciências no Brasil e suas metodologias. Ijuí: Editora UNIJUÍ, p. 89-122, 2006.

MICELI, B. S.; ROCHA, M. B. Análise da natureza da ciência em textos de divulgação científica sobre genética inseridos em livros didáticos. REnCiMa, 2020.

MICELI, B.; ROCHA, M. B. Análise de textos de divulgação científica sobre genética inseridos em livros didáticos de biologia. Alexandria: Revista de Educação em Ciência e Tecnologia, v. 12, n. 2, p. 121-138, 2019. 
MORAES, F. N. et al. Teste genético preditivo de câncer de mama: uma abordagem discursiva sobre o uso de texto de divulgação científica e histórias em quadrinhos no ensino. Temas em Educação e Saúde, p. 194-203, 2019.

NASCIMENTO, L. O. Eclipse Solar de 1919 em revistas de divulgação científica: concepções sobre natureza da Ciência e possíveis implicações para o ensino de Ciências. Revista de Ensino de Ciências e Matemática, v. 10, n. 1, p. 116-129, 2019.

SANTOS, W. L. P. Educação científica na perspectiva de letramento como prática social: funções, princípios e desafios. Revista brasileira de educação, v. 12, p. 474492, 2007.

SILVA, W. M.; ZANOTELLO, M. Discursos sobre Física Contemporânea no Ensino Médio a partir da Leitura de Textos de Divulgação Científica. Revista Brasileira de Pesquisa em Educação em Ciências, p. 45-74, 2017.

SOUZA, P. H. R.; ROCHA, M. B. Análise da linguagem de textos de divulgação científica em livros didáticos: contribuições para o ensino de biologia. Ciência \& Educação (Bauru), v. 23, p. 321-340, 2017.

SOUZA, P. H. R.; ROCHA, M. B. O caráter híbrido dos textos de divulgação científica inseridos em livros didáticos. Ciência \& Educação (Bauru), v. 24, p. 1043-1063, 2018.

TARGINO, A. R. L.; GIORDAN, M. Retextualização do texto literário de divulgação científica A Tabela Periódica no ensino de Química1. Educação e Pesquisa, v. 47, 2021.

ZANCAN, G. T. Educação científica: uma prioridade nacional. São Paulo em perspectiva, v. 14, p. 3-7, 2000. 